\title{
How transparent are central banks?
}

\author{
Sylvester C.W. Eijffinger ${ }^{\text {a,b,c,d }}$, Petra M. Geraats ${ }^{\text {e,* }}$ \\ ${ }^{a}$ CentER, Tilburg University, PO Box 90153, 5000 LE, Tilburg, The Netherlands \\ ${ }^{\mathrm{b}}$ RSM Erasmus University, PO Box 1738, 3000 DR Rotterdam, The Netherlands \\ c CEPR, London, UK \\ ${ }^{\mathrm{d}}$ CESifo, Munich, Germany \\ e Faculty of Economics, University of Cambridge, Cambridge, CB3 9DD, UK
}

Received 30 April 2004; accepted 27 September 2005

Available online 23 November 2005

\begin{abstract}
Central bank transparency has become the topic of a lively public and academic debate on monetary policy. However, this has been complicated by the fact that transparency is a qualitative concept that is hard to measure. This paper proposes an index for the transparency of monetary policy that comprises the political, economic, procedural, policy and operational aspects of central banking. The index is compiled for nine major central banks. It is based on a detailed analysis of actual information disclosure and reveals a rich variety in the degree and dynamics of central bank transparency.
\end{abstract}

(C) 2005 Elsevier B.V. All rights reserved.

JEL classification: E52; E58

Keywords: Monetary policy; Transparency

\section{Introduction}

Central bank transparency has become the topic of a lively public and academic debate on monetary policy. The public demands transparency to achieve accountability of central banks that have increasingly become independent. In addition, a burgeoning academic literature has analyzed the economic consequences of greater transparency of monetary policy. The debate on transparency has been complicated by the fact that it is a qualitative concept for which few measures exist. This paper proposes an index for the transparency of monetary policy that comprises the political, economic, procedural, policy and operational aspects of central banking.

* Corresponding author. Tel.: +44 1223 335295; fax: +44 1223335475.

E-mail address: Petra.Geraats@econ.cam.ac.uk (P.M. Geraats). 
The index is compiled for nine major central banks for 5 years (1998-2002) and is based on a scrutiny of actual information disclosure. It reveals the various ways in which central banks have become transparent and how transparency is evolving over time.

To give a sneak preview of our findings, the most transparent central banks in our sample are the Reserve Bank of New Zealand, the Swedish Riksbank and the Bank of England. The subtop is formed by the Bank of Canada, the European Central Bank and the Federal Reserve. The least transparent central banks are the Reserve Bank of Australia, the Bank of Japan and the Swiss National Bank. Although the most transparent central banks are all inflation targeters, this monetary policy framework appears neither a necessary nor a sufficient condition for transparency.

An important advantage of our transparency index is that it is based on a theory-consistent framework and distinguishes various aspects of transparency based on the role that information plays in the monetary decision making process. This makes our index better suited to test predictions from the theoretical literature. In addition, it allows us to identify how central banks differ in their emphasis of various aspects, independent of their monetary policy framework, and how greater transparency manifests itself over time.

There are several other papers that provide useful descriptions of central bank transparency in practice. Bernanke, Laubach, Mishkin, and Posen (1999) provide a well structured description in the form of case studies but focus their analysis on inflation targeting. An elaborate informal discussion and review of central bank transparency is presented by Blinder, Goodhart, Hildebrand, Lipton, and Wyplosz (2001). They give a detailed account of transparency at the Federal Reserve, the European Central Bank, the Bank of Japan, the Bank of England and the Reserve Bank of New Zealand, but do not provide any measure for the degree of transparency.

In their comprehensive survey of 94 central banks, Fry, Julius, Mahadeva, Roger, and Sterne (2000) construct an index of 'policy explanations' that consists of three components: (i) explanations of policy decisions, (ii) explanations in forecasts and forward-looking analysis, and (iii) explanations in published assessments and research. Their index captures many transparency issues, but does not highlight the role of information in the decision-making process. In addition, their index is constructed using survey responses from central banks, whereas our results stem from an independent analysis of the actual information disclosed by central banks.

In addition, Bini-Smaghi and Gros (2001) present an indicator of central bank transparency and accountability for six major central banks that captures four components: objectives, strategy, publication of data and forecasts, and communication strategy. ${ }^{1}$ The latter captures diversity in the medium of information disclosure, regardless of how informative the disclosures are. In contrast, our transparency index focuses on the contents of information disclosure.

Fracasso, Genberg, and Wyplosz (2003) evaluate the inflation reports of 20 central banks that have adopted inflation targeting. They assess the quantity, quality and accessibility of the information provided, the clarity of assumptions about key macroeconomic variables, the presentation of the policy-making process, and the executive summary. In addition, they provide an overall rating of each inflation report based on its persuasiveness, expertise, completeness, writing style and information. Their analysis considers many facets of communication but is confined to inflation reports. Instead, our index focuses on the informativeness about each stage of the policymaking process and covers all public communication by central banks.

\footnotetext{
${ }^{1}$ de Haan and Amtenbrink (2002) suggest a variation on this index. In addition, de Haan, Amtenbrink, and Eijffinger (1999) provide an index of central bank accountability that includes some elements that pertain to transparency.
} 
Last but not least, we are the first to provide a monetary policy transparency index that covers several years (1998-2002). It reveals interesting dynamics and establishes that transparency has increased considerably for several central banks but not in all respects.

The remainder of the paper is organized as follows. Section 2 discusses the conceptual framework that is used to motivate our index of central bank transparency, which is presented in Section 3. The index is used in Section 4 to show how transparent central banks are. Section 5 provides a critical discussion of the results and Section 6 concludes.

\section{Conceptual framework}

Transparency of monetary policy can be defined as the extent to which central banks disclose information that is related to the policymaking process. It is a multifaceted concept that could pertain to any aspect of monetary policymaking. Thus, it seems natural to use a conceptual framework that reflects the different stages of the decision-making process. Following Geraats (2002), one can distinguish five aspects of transparency: political, economic, procedural, policy and operational transparency. These aspects of transparency correspond to information disclosure about the stages of monetary policymaking illustrated in Fig. 1.

- Political transparency refers to openness about policy objectives. This comprises a statement of the formal objectives of monetary policy, including an explicit prioritization in case of potentially conflicting goals, and quantitative targets. Political transparency is enhanced by institutional arrangements, like central bank independence and central bank contracts, because they ensure that there is no undue influence or political pressure to deviate from stated objectives. $^{2}$

- Economic transparency focuses on the economic information that is used for monetary policy. This includes the economic data the central bank uses, the policy models it employs to construct economic forecasts or evaluate the impact of its decisions, and the internal forecasts the central bank relies on. The latter are particularly important since monetary policy actions are known to take effect only after substantial lags. So, the central bank's actions are likely to reflect anticipated developments.

- Procedural transparency is about the way monetary policy decisions are taken. It involves an explicit monetary policy rule or strategy that describes the monetary policy framework, and an account of the actual policy deliberations and how the policy decision was reached, which is achieved by the release of minutes and voting records.

- Policy transparency means a prompt announcement of policy decisions. In addition, it includes an explanation of the decision and a policy inclination or indication of likely future policy actions. The latter is relevant because monetary policy actions are typically made in discrete steps; a central bank may be inclined to change the policy instrument, but decide to wait until further evidence warrants moving a full step.

- Operational transparency concerns the implementation of the central bank's policy actions. It involves a discussion of control errors in achieving the operating instrument or target set in

\footnotetext{
${ }^{2}$ Note that political transparency need not be under control of the central bank, but is often determined by political authorities (government or legislature). For instance, Anglo-Saxon central banks typically do not have goal independence and lack the ability to set their own quantitative targets.
} 


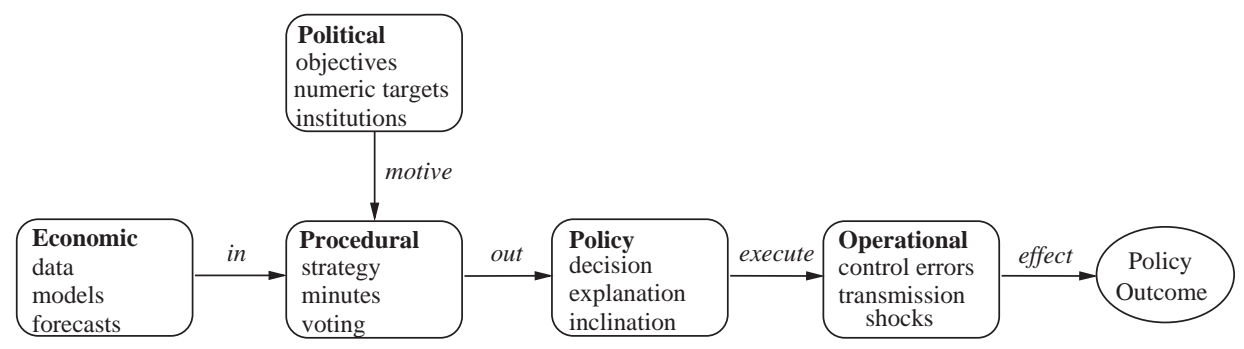

Fig. 1. A conceptual framework for the monetary policymaking process.

the policy decision, and (unanticipated) macroeconomic disturbances that affect the transmission of monetary policy from instrument to outcome. ${ }^{3}$

It is useful to show how each of these aspects features in a canonical model. Consider a central bank with the objective function

$$
W=\alpha\left(\pi-\pi^{*}\right)^{2}+\beta\left(y-y^{*}\right)^{2}
$$

where $\pi$ is inflation and $y$ is output. An important component of political transparency is the publication of the inflation target $\pi^{*}$. In addition, institutional arrangements also matter because they clarify the motives of monetary policymakers. In particular, central bank independence ensures that central bankers can pursue (1) without political influence, and incentive schemes effectively modify their objective function (1).

The structure of the economy could be represented by the aggregate demand and supply equations

$$
\begin{aligned}
& y=\overline{\mathrm{y}}-a\left(i-\pi^{e}-\overline{\mathrm{r}}\right)+d \\
& \pi=\pi^{\mathrm{e}}+b(y-\overline{\mathrm{y}})+s
\end{aligned}
$$

where $i$ is the nominal interest rate and $\pi^{\mathrm{e}}$ denote inflation expectations. ${ }^{5}$ The natural rate of output is $\bar{y}$ and the long-run real interest rate equals $\overline{\mathrm{r}}$. In addition, there are aggregate demand shocks $d$ and aggregate supply shocks $s$. Economic transparency means that the private sector has the same knowledge about the economy as the central bank. This includes both the structure of the economy and the part of the disturbances $d$ and $s$ that are anticipated by the central bank and reflected in its actions. ${ }^{6}$

\footnotetext{
${ }^{3}$ Another kind of operational transparency that could potentially be considered is the publication of money market interventions that are made to implement policy decisions. However, this issue of market transparency is not included in our transparency index which focuses more on macroeconomic aspects.

${ }^{4}$ Perfect political transparency would require that the output target $y^{*}$, relative preferences $\alpha / \beta$ and the functional form of the objective function are also known to the private sector, but in practice, no central banks are transparent in this respect. See Cukierman (2002) for a discussion and potential explanation.

${ }^{5}$ The structure of the economy determines the transmission mechanism. Cukierman (2002) provides a comparison of three popular models: neo-monetarist Lucas-type transmission, the neo-Keynesian model with backward-looking pricing, and the new-Keynesian model with forward-looking pricing.

${ }^{6}$ If the central bank's behavior is not certainty-equivalent, uncertainty about the economy should be conveyed as well.
} 
Assume that the nominal interest rate $i$ is used as monetary policy instrument. The central bank could set it based on a Taylor-type instrument rule, or it could maximize (1) subject to (2) and (3), adopting a Svensson (2002) style targeting frame-work that allows for judgement. Alternatively, the central bank could use different procedures and formulate its own monetary policy strategy. In the case of procedural transparency, the central bank's strategy and other procedural aspects like minutes and voting records are shared with the private sector.

In the context of the canonical model, policy transparency means that the central bank promptly announces its decision about the policy instrument $i$. When interest rate movements are restricted to discrete increments, a policy inclination is also relevant.

Finally, the implementation of monetary policy could be complicated by control errors pertaining to the policy instrument, or transmission disturbances in the form of unanticipated aggregate demand and supply shocks $d$ and $s$. Operational transparency means that these control errors and transmission disturbances are communicated to the public.

This stylized model shows that all five aspects of our conceptual framework can be distinguished in theory and that each is required for an adequate analytical description of monetary policy. Our index, which is presented in Section 3, provides a way to quantify central bank transparency for each of these five aspects. Of course, the construction of any index reflects some subjective choices. We decided to distinguish the different aspects of transparency to focus on the role of information in the decision process of the central bank. This makes our index closer to the theoretical literature and more amenable to an empirical evaluation of transparency models than existing indices.

In principle, the motives for and effects of transparency could differ for each of the five aspects (see the survey by Geraats (2002)). Theoretical arguments indicate that political, economic and operational transparency could enhance credibility of low-inflation monetary policy, procedural transparency may improve the quality of decision-making, and policy transparency could boost the effectiveness of interest rate setting. The fact that some aspects of transparency could have a similar effect suggests that there may be some degree of substitutability. However, the theoretical literature shows that such substitutability is not straightforward. For instance, Geraats (2005) finds that economic transparency improves the central bank's incentives to invest in reputation and leads to lower inflation, but that greater transparency about preferences has the opposite effect. Ultimately, the relevance of (aspects of) transparency is an empirical matter that our index may help to resolve.

It is important to emphasize that greater transparency may not be desirable. The comprehensive survey by Geraats (2002) explains the great variety of theoretical findings in the literature, depending on the aspect considered and the structure of the model. ${ }^{7}$ For example, transparency about supply shocks is detrimental when it affects the contemporaneous aggregate supply equation, because it hampers output stabilization. Furthermore, the public announcement of noisy information (e.g. a highly uncertain future interest rate path) could lead to greater variability and reduce social welfare when agents discard private information to coordinate their actions (Morris and Shin, 2002). However, the theoretical literature has also identified potential benefits of transparency. In particular, it could lead to lower inflation and enhance the central bank's reputation; it may give the central bank greater flexibility to stabilize economic shocks and reduce the volatility of output; it reduces private sector uncertainty; and it allows for greater accountability which makes it possible to align the actions of central bankers closer to socially optimal monetary policy.

\footnotetext{
${ }^{7}$ See also the interesting informal discussions by Goodfriend (1986) and Winkler (2002).
} 
Although many central banks have become remarkably transparent during the last decade, the question whether transparency is always beneficial is still an open issue. Empirical research is needed to evaluate the relevance of the theoretical arguments advanced in the literature, but that requires a theory-consistent measure of transparency, which we provide.

\section{Central bank transparency index}

The degree of transparency could be measured by analyzing either formal disclosure requirements or actual practices. This paper pursues the latter approach because the information disclosure by central banks tends to go far beyond legal requirements. The public communications by central banks greatly vary in their informativeness, so we concentrate on the contents rather than the medium of information disclosure.

The informativeness of central bank communications could be assessed from the perspective of the public using financial market responses. However, this makes it hard to identify in what respects a particular central bank is not transparent, because useful information that is not disclosed produces no market reaction. Instead, we focus on the information contents from the perspective of the monetary policy-maker. In particular, we evaluate whether official monetary policy announcements and publications contain explicit information that is relevant for the monetary policymaking process.

Our index closely follows the framework discussed in Section 2 and provides a measure of political, economic, procedural, policy and operational transparency. The subindex for each of the five aspects is based on three questions, which each have equal weight and a maximum score of one. A comprehensive measure of transparency is obtained by the sum of the five subindexes, so it has a maximum score of fifteen. The index covers each of the fourteen items that are organized by aspect in Fig. 1, supplemented by one question that addresses whether there is a published evaluation of the policy outcome based on policy objectives. The Appendix contains the complete description of our index for monetary policy transparency, including the exact questions and criteria that we used. ${ }^{8}$

The index is constructed for nine major central banks: the Reserve Bank of Australia (RBA), the Bank of Canada (BoC), the European Central Bank (ECB), the Bank of Japan (BoJ), the Reserve Bank of New Zealand (RBNZ), the Swedish Riksbank (SRB), the Swiss National Bank (SNB), the Bank of England (BoE), and the U.S. Federal Reserve (Fed). Resource constraints forced us to consider only a limited number of central banks. We chose the eight central banks that are most important in international financial markets, measured in terms of foreign exchange market turnover of their currencies in April 2001. In addition, we included the Reserve Bank of New Zealand because of its pioneering role in central bank transparency starting in 1989.

Our methodology was as follows. First, we sifted through all information published by central banks and other relevant government sources, that was freely available in English as of June 2001. ${ }^{9}$ Second, for each central bank, we sent the scores we had obtained for that central bank together with the detailed description of the transparency index to a senior official at that central

\footnotetext{
${ }^{8}$ The detailed information and sources used to construct the transparency index for each central bank are available in the Supplementary Data appendix of the unabridged version of this paper (Eijffinger and Geraats, 2004).

${ }^{9}$ It is important that all relevant information is not only available in the local language but also in the lingua franca of international financial markets, English. This language criterion only seems to affect index scores in one instance, given in footnote 24.
} 
bank (chief economist, or comparable) with the request to review the scores. Third, we used the responses to reassess our scores and made a few modifications. ${ }^{10}$ Later on, we updated the index for 2002 and went back to 1998. This methodology is very time consuming, but it has the advantage that it is based on an independent scrutiny of information sources, complemented by the expert feedback from central banks, leading to accurate scores. ${ }^{11}$

Tables 1 and 2 show the 1998 index and the 1998-2002 increase in the transparency index for each central bank by aspect. The detailed transparency scores for 2002 are presented in Table 3. We first discuss each aspect of transparency, providing a cross-section overview. Subsequently, we consider the transparency of each central bank in Section 4.

\subsection{Political transparency}

All central banks in our sample have formal objectives for monetary policy (1.a). However, Japan, Switzerland, the United States (and Sweden in 1998) do not achieve the full score of one on this item because they have multiple objectives without a prioritization. The latter is important because objectives can be conflicting. The other central banks identify price stability as their main objective.

The specification of a quantitative target for the main objective(s) of monetary policy (1.b) is popular. With the exception of the Bank of Japan, (the Swiss National Bank until 1999) and the Federal Reserve, all central banks in our sample have a quantitative target for inflation. This target could be set by the central bank (ECB, SRB, SNB), the government (BoE), or be based on a joint agreement (RBA, BoC, RBNZ).

The institutional arrangements between the monetary authorities and the government (1.c) mostly take the form of explicit instrument independence. For several central banks (RBA, $\mathrm{BoC}, \mathrm{RBNZ}, \mathrm{BoE}$ ) independence is subject to an explicit over-ride mechanism that specifies a formal (typically restrictive) procedure for the government to overrule the monetary policy decision of the central bank. Although it is sometimes argued that this curtails central bank independence and could affect the incentives of the central bank, an override clause that is explicit does not reduce transparency about the institutional setting. The United States (and initially also Sweden and Switzerland) do not enjoy explicit instrument independence, so they are not awarded the full score of one. ${ }^{12}$

Many central banks now get the maximum score of three on political transparency, including the Reserve Bank of Australia, the Bank of Canada, the European Central Bank, the Reserve Bank of New Zealand, the Riksbank and the Bank of England. These are all central banks that have adopted 'inflation targeting', with the exception of the ECB. A particularly interesting case is New Zealand, which clarifies institutional arrangements in the form of a central bank contract called Policy Targets Agreement (PTA). It even allows the government to fire the Reserve Bank Governor if the inflation target is not met.

\footnotetext{
${ }^{10}$ We adjusted only 4 out of 135 scores, three of which concerned item 2.a for which publicly available information in English appeared hard to find for Japan, Sweden and Switzerland. In addition, we found information relevant for item 5.a at a regional U.S. Federal Reserve Bank.

${ }^{11}$ The fact that every central bank claimed to deserve a higher score (up to 5 points extra) underscores the importance of an independent analysis.

${ }^{12}$ Nevertheless, the Fed is often thought to enjoy effective independence from the government and Congress. Although this is not based on formal instrument independence, it could be induced by the anticipation of negative reactions from Wall Street if the Fed is put under political pressure.
} 
Table 1

Central bank transparency index, June 1998

\begin{tabular}{|c|c|c|c|c|c|c|}
\hline 1998 Index & Political & Economic & Procedural & Policy & Operational & Total \\
\hline Australia & 3 & 1 & 1 & 1.5 & 1.5 & 8 \\
\hline Canada & 3 & 2.5 & 1 & 2 & 2 & 10.5 \\
\hline Euro zone* & 3 & 1 & 1 & 1.5 & 2 & 8.5 \\
\hline Japan & 1.5 & 1 & 2 & 1.5 & 2 & 8 \\
\hline New Zealand & 3 & 2.5 & 3 & 1 & 1 & 10.5 \\
\hline Sweden & 2 & 1.5 & 2 & 1.5 & 2 & 9 \\
\hline Switzerland & 1 & 1 & 1 & 2 & 1 & 6 \\
\hline United Kingdom & 3 & 1.5 & 3 & 1.5 & 2 & 11 \\
\hline United States & 1 & 2.5 & 2 & 1.5 & 1.5 & 8.5 \\
\hline
\end{tabular}

* Euro zone index for 1999 .

\subsection{Economic transparency}

The economic information that is used for monetary policy includes timely economic data (2.a). We looked for the publication of quarterly time-series of five key variables that the academic literature considers important for monetary policy and that cannot be directly observed in financial markets: money supply, inflation, GDP, unemployment rate and capacity utilization. ${ }^{13}$ The most common reason for not getting the full score is that data on capacity utilization is not disclosed.

To interpret the central bank's policy actions it is important to know what kind of policy models it employs (2.b). An increasing number of central banks have published a structural macroeconomic model that is used for policy analysis; only Japan, Sweden and Switzerland remain deficient in this respect.

All central banks release numerical internal forecasts for inflation and/or output (2.c). However, only the Reserve Bank of New Zealand, the Riksbank and the Bank of England publish medium term forecasts for both inflation and output at quarterly frequency and specify the underlying assumptions about the policy instrument, which we require for the maximum score. ${ }^{14,15}$ This requirement is motivated by the fact that inflation and output tend to be the key variables in the determination of monetary policy and that they can only be affected in the medium term (1 to 3 years ahead). In addition, quarterly updates of forecasts are required given that a significant amount of macroeconomic data (including national accounts) are available at quarterly frequency.

There has been a significant increase in economic transparency over time (from an average of 1.7 in 1998 to 2.3 in 2002). Only two central banks attain the maximum score of 3 on economic transparency, the Reserve Bank of New Zealand and the Bank of England. The latter deserves special mention; it provides extensive documentation on its economic models, including the

\footnotetext{
${ }^{13}$ Although the data may be produced outside the central bank, its release contributes to the transparency of the central bank's policymaking. A few central banks claimed they do not use any measures of capacity utilization, but given the prominence of the output gap in theoretical models they must have some opinion about it to make appropriate monetary policy decisions.

${ }^{14}$ When the policy instrument is the interest rate, central bank forecasts for both inflation $\pi$ and output $y$ are generally needed to identify demand and supply shocks, $d$ and $s$, and achieve economic transparency (Geraats, 2005). But that would not suffice when the instrument is the money supply.

${ }^{15}$ We do not discriminate between conditional vs unconditional forecasts or staff vs policymakers' forecasts, although we recognize that these may serve different purposes in the communication strategy. In the absence of certainty equivalence, risks to forecasts would also be relevant.
} 
Table 2

Increase in central bank transparency index, June 1998-June 2002

\begin{tabular}{|c|c|c|c|c|c|c|}
\hline Change in index & Political & Economic & Procedural & Policy & Operational & Total \\
\hline Australia & 0 & +1 & 0 & 0 & 0 & +1 \\
\hline Canada & 0 & 0 & 0 & 0 & 0 & 0 \\
\hline Euro zone* & 0 & +1.5 & 0 & +0.5 & 0 & +2 \\
\hline Japan & 0 & +0.5 & 0 & 0 & -0.5 & 0 \\
\hline New Zealand & 0 & +0.5 & 0 & +2 & +1 & +3.5 \\
\hline Sweden & +1 & +0.5 & +1 & +1.5 & +1 & +5 \\
\hline Switzerland & +1.5 & +0.5 & 0 & 0 & -0.5 & +1.5 \\
\hline United Kingdom & 0 & +1.5 & 0 & 0 & +0.5 & +2 \\
\hline United States & 0 & 0 & 0 & +1.5 & 0 & +1.5 \\
\hline
\end{tabular}

* Euro zone change in index from 1999 to 2002.

computer code for its macroeconometric model. Furthermore, the Bank of England was the first central bank to introduce fan charts for its internal forecasts of inflation and output, which has set an example for several other central banks.

\subsection{Procedural transparency}

Most of the central banks in our sample provide a description of their monetary policy framework in the form of an explicit monetary policy strategy (3.a). Typically, the strategy is

Table 3

Index of central bank transparency, June 2002

Central bank transparency Australia Canada Euro zone Japan New Zealand Sweden Switzerland UK US

\begin{tabular}{llllllllll}
\hline 1. Political & 3 & 3 & 3 & 1.5 & 3 & 3 & 2.5 & 3 & 1
\end{tabular}

a. Formal objectives

0.51

b. Quantitative targets

$\begin{array}{ll}1 & 1 \\ 1 & 1\end{array}$

c. Institutional arrangements 1

2. Economic

a. Economic data

b. Policy models

c. Central bank forecasts

$\begin{array}{lllll}2 & \mathbf{2 . 5} & \mathbf{2 . 5} & \mathbf{1 . 5} & \mathbf{3} \\ 0.5 & 1 & 1 & 1 & 1 \\ 1 & 1 & 1 & 0 & 1 \\ 0.5 & 0.5 & 0.5 & 0.5 & 1\end{array}$

3. Procedural

a. Explicit strategy

b. Minutes

c. Voting records

4. Policy

a. Prompt announcement

b. Policy explanation

c. Policy inclination

5. Operational

a. Control errors

b. Transmission disturbances 0.5

c. Evaluation policy outcome 0

1
1
0
0

$\begin{array}{llll}\mathbf{1} & \mathbf{1} & \mathbf{2} & \mathbf{3} \\ 1 & 1 & 0 & 1 \\ 0 & 0 & 1 & 1 \\ 0 & 0 & 1 & 1\end{array}$

$\begin{array}{lll}1.5 & 2 & 2\end{array}$

1

0

1
1
1

0.5

1


some form of inflation targeting, although the ECB's "two pillar strategy" is a notable exception. Only the Bank of Japan and the Federal Reserve do not have an explicit monetary policy framework.

Several central banks, in particular the Bank of Japan, the Riksbank, the Bank of England and the Federal Reserve, release a comprehensive account of policy deliberations within a reasonable amount of time (eight weeks) in the form of (non-attributed) minutes (3.b) that also include a discussion of the forward-looking arguments that are so critical for monetary policy. ${ }^{16}$

These central banks are also the ones that publish individual voting records (3.c). ${ }^{17}$

Three central banks score full marks on procedural transparency, the Reserve Bank of New Zealand, the Riksbank and the Bank of England. The Reserve Bank of New Zealand is special in the sense that its policy decisions are solely made by its Governor. This means that voting records are immaterial. In addition, minutes are substituted by comprehensive explanations of its decisions, including forward-looking analysis. Although decision-making by committee makes it harder to achieve procedural transparency, the Riksbank and the Bank of England show that this need not be an insurmountable problem.

\subsection{Policy transparency}

All central banks make a prompt announcement of their policy decisions (4.a); their operating instrument or target is a short-term nominal interest rate, with the Bank of Japan currently being the only exception. However, there has not always been openness about policy decisions. The Federal Reserve, for instance, only adopted this practice in 1994.

Most central banks provide an explanation when they announce their policy decisions (4.b). The Reserve Bank of Australia, the Bank of Japan and the Bank of England do not get the full score because they do not give an explanation after all policy decisions, although they do provide one whenever policy decisions change.

The publication of a policy inclination or indication of likely future policy actions (4.c) is unusual. The Federal Reserve includes a statement in its policy announcements that reflects its policy tilt, but only since May 1999. The Riksbank also provides a policy inclination since May 2002. The Reserve Bank of New Zealand adopts a different approach and provides short-run quarterly forecasts of short-term nominal interest rates, which essentially convey its likely future policy actions. These three central banks get full marks on policy transparency. ${ }^{18}$ And the clear increase in the average score on policy transparency (from 1.6 in 1998 to 2.2 in 2002) is mainly the result of significant changes by these central banks.

\subsection{Operational transparency}

The implementation of monetary policy could be complicated by two kinds of disturbances, control errors in achieving the operating instrument or target set in the

\footnotetext{
${ }^{16}$ We do not require the publication of attributed minutes or even verbatim transcripts because they are likely to discourage open discussion during monetary policy meetings (Buiter, 1999, p. 194).

${ }^{17}$ A few central banks told us they decide 'by consensus'. However, this term is ambiguous and need not mean unanimity. In fact, decision making by unanimity would be at odds with many central bank statutes that stipulate decisions be taken by majority voting.

18 A few central banks suggested that the risks to forecasts they publish indicate a policy inclination. However, it is not straightforward to map risks to inflation and output forecasts into a policy tilt, especially when they go in opposite directions.
} 
policy decision (5.a) and unanticipated macroeconomic disturbances that affect the transmission of monetary policy (5.b). Most central banks in our sample account for significant deviations from the operating target (if any), or have (nearly) perfect control over their main operating instrument. The only exceptions are the Bank of Japan (since March 2001, when it adopted a money target) and the Swiss National Bank (since December 1999, when it adopted a wide interest rate range), which fall short because they do not provide explanations for significant fluctuations around the operating target, thereby getting a score of one-half.

Most central banks regularly publish an analysis of current macroeconomic developments or short-term forecasts, which implicitly provide information on trans-mission disturbances (5.b). Nevertheless, two central banks get a score of zero: the Federal Reserve releases its short-run forecasts and macroeconomic analysis only semiannually; and the Swiss National Bank only has a brief abstract of macroeconomic analysis in English. The Riksbank and the Bank of England both obtain the full score as they include an annual discussion of past forecast errors, which is needed for a complete explanation of the unanticipated factors affecting the transmission process.

Finally, we consider whether central banks regularly provide an evaluation of the policy outcome in light of macroeconomic objectives (5.c). Most central banks have some kind of evaluation without accounting for the role of monetary policy. The Reserve Bank of Australia and the Swiss National Bank are exceptions in the sense that they do not have a regular evaluation. On the other hand, the Riksbank sets a positive example with its explicit annual evaluation in which it discusses the contribution of monetary policy in meeting the objectives, thereby earning the maximum score.

All in all, the Riksbank is the only central bank to achieve full marks on operational transparency. Perhaps, it could be a source of inspiration for other central banks, since the scores on operational transparency vary a lot, with the Swiss National Bank getting the lowest score (0.5) for any of the five aspects.

The comprehensive index that consists of the sum of the subscores for each of the five aspects reveals which central banks are the most transparent. In 1998, the most transparent central banks were the Bank of England (11 out of 15), the Reserve Bank of New Zealand and the Bank of Canada (both 10.5), followed by the Swedish Riksbank (9), the Federal Reserve (8.5), the Reserve Bank of Australia and Japan (both 8) and Switzerland (6). In 2002, average transparency had increased from 8.9 to 10.7 , with major rises in economic and policy transparency. The top league of central bank transparency now consists of the Reserve Bank of New Zealand, the Riksbank (both 14) and the Bank of England (13). The subtop is formed by the Bank of Canada, the European Central Bank (both 10.5) and the Federal Reserve (10). The Reserve Bank of Australia (9), the Bank of Japan (8) and the Swiss National Bank (7.5) remain the least transparent central banks in our sample. Table 2 shows that most of the increase in average transparency from 1998 to 2002 can be attributed to greater economic transparency by many central banks and large increases in policy transparency by a few central banks.

\section{How transparent are central banks?}

The Previous section provided an overview of each aspect of transparency across central banks. This section complements that view with a description of transparency for each central bank during 1998-2002. 


\subsection{Reserve Bank of Australia}

Although the Reserve Bank of Australia has adopted inflation targeting, it gets one of the lowest transparency scores (8, increasing to 9 in 2002) in our sample. Although the RBA gets the maximum score on political transparency, its openness on other aspects is much less. Economic transparency falls short because it does not publish quarterly data on capacity utilization and only provides rough short term forecasts for inflation (quarterly) and output (semiannually) without numerical details about the medium term. In addition, there was no explicit policy model until October 2001. ${ }^{19}$ Procedural transparency is low as the RBA does not release minutes and voting records. There is also scope for greater policy transparency because of the lack of an explicit policy inclination and a prompt explanation of each policy decision. Regarding operational transparency, the RBA provides neither a discussion of past forecast errors, nor an evaluation of the policy outcome.

The Reserve Bank of Australia shows that inflation targeting by no means guarantees transparency in all respects.

\subsection{Bank of Canada}

The Bank of Canada, another inflation targeter, secures a place in the subtop of transparency with a score of 10.5. It earns the full score on political transparency, but misses out on complete economic transparency because it only publishes rough projections for inflation and output without full numerical details for the medium term. The BoC has low procedural transparency because it does not disclose minutes and voting records. It does better on policy transparency, although there is no explicit indication of likely future policy actions. For operational transparency the BoC misses full marks for not discussing past forecast errors and not explicitly accounting for deviations of inflation from the target.

All in all, the Bank of Canada is quite transparent, but its procedural transparency is low.

\subsection{European Central Bank}

Starting of with a relatively low score of 8.5 , the European Central Bank has significantly increased its transparency and now belongs to the subtop with a score of 10.5. Although it is not an inflation targeter, it achieves the maximum score on political transparency. For economic transparency the ECB earns high marks, but this is entirely due to recent developments, namely the publication of its euro area model (in January 2001) and its semiannual medium term conditional staff projections for inflation and output (in December 2000). Procedural transparency at the ECB is limited because it does not provide comprehensive minutes and actual voting records. Policy transparency at the ECB has increased a bit as it now provides an explanation of the policy decision at a press conference after each monetary policy meeting, but it still lacks an explicit policy inclination. On operational transparency, there is no discussion of past forecast errors and no explicit account of the contributions of monetary policy in the informal evaluation of policy outcomes the ECB provides.

\footnotetext{
19 Although a structural macroeconomic model appears in one of its Research Discussion Papers (2000-05), it was not made clear until October 2001 that the Bank uses it for policy analysis.
} 
In its early years of existence, the European Central Bank has already achieved quite some transparency in several respects, but there is scope for greater procedural and policy transparency. $^{20}$

\subsection{Bank of Japan}

The Bank of Japan has one of the lowest transparency scores (8) in our sample. Political transparency is limited because it has multiple objectives of monetary policy without explicit prioritization, and no precise definition or quantification of its objectives. The BoJ has shown some increase in economic transparency. It still does not disclose a formal macroeconomic model used for policy analysis, but since October 2000 the BoJ has published its forecasts for inflation and output, albeit only at semiannual frequency. Procedural transparency at the BoJ is quite high because it publishes elaborate minutes in a timely fashion, including individual voting records, although it lacks an explicit monetary policy strategy. Concerning policy transparency, there is no explicit policy inclination or a prompt explanation of each policy decision. The score on operational transparency of the BoJ has dropped a bit because after changing the main operating target to the outstanding balance of current accounts at the Bank in March 2001, there have been significant fluctuations without explanations for it. ${ }^{21}$ In addition, the BoJ does not discuss past forecast errors or account for deviations between policy outcomes and objectives.

The Bank of Japan has recently shown some change in transparency, but its transparency is still limited, most noticeably on political and policy aspects.

\subsection{Reserve Bank of New Zealand}

The Reserve Bank of New Zealand, which has been one of the most transparent central banks throughout our sample, started off with a score of 10.5 in 1998, zoomed ahead to 13 in 1999 and subsequently rose to 14 points. The RBNZ is an inflation targeter that has attained the full score on political, economic, procedural and policy transparency. The RBNZ accomplished an impressive increase in policy and operational transparency in March 1999 when it altered its monetary policy operating procedures. In particular, it changed its formal policy instrument from the daily settlement cash target, which had not been adjusted for a long time and was hardly mentioned in RBNZ communications, to the Official Cash Rate. ${ }^{22}$ But, the RBNZ still misses marks on operational transparency because it does not provide a discussion of past forecast errors or evaluate how monetary policy contributed to policy outcomes.

The transparency of the Reserve Bank of New Zealand is outstanding, although it is still feasible to increase operational transparency.

\footnotetext{
${ }^{20}$ This also sheds light on the debate on ECB transparency between Buiter (1999) and Issing (1999), which is discussed by de Haan and Eijffinger (2000).

${ }^{21}$ Previously, the BoJ had a main operating target for the uncollateralized overnight call rate, with the rate at essentially zero since February 1999.

${ }^{22}$ Instead of focusing on the formal policy instrument, from December 1996 to March 1999 the monetary policy stance was essentially conveyed in terms of a target for the Monetary Conditions Index (MCI), which is a weighted average of the trade-weighted exchange rate and the 90-day interest rate. In terms of this (intermediate) policy target, policy and operational transparency in 1998 were much better (3 and 2, respectively).
} 


\subsection{Swedish Riksbank}

The Swedish Riksbank has achieved the largest increase in transparency in our sample. Starting with a modest score of 9 in 1998, the SRB has soared to 14, sharing the top spot with New Zealand. It is also an inflation targeter with a maximum score on political transparency. But the SRB could still increase economic transparency because it does not disclose a formal macroeconomic model that is used for policy analysis. Regarding procedural transparency, the SRB has recently reached the full score, releasing both minutes and voting records. ${ }^{23}$ On policy transparency, the SRB also recently achieved the maximum score after it started providing an explicit policy tilt. For operational transparency the Riksbank is the only central bank to gain full marks; since 1999, it provides an annual evaluation of the inflation outcome over the last three years, including a discussion of the role of monetary policy.

The Swedish Riksbank has accomplished an impressive increase in transparency. It attains perfect scores on all aspects, except for economic transparency because it does not publish a policy model.

\subsection{Swiss National Bank}

The Swiss National Bank receives the lowest transparency score in our sample with 7.5 points. Political transparency increased significantly in 2000, when the SNB's independence was enshrined in the constitution and a quantitative definition of price stability was specified. But the SNB still has multiple objectives without an explicit prioritization. On economic transparency, the SNB has published a 3-year forecast for inflation at semiannual frequency since 1999, but it does not disclose a formal policy model. The SNB has low procedural transparency because it releases neither minutes nor voting records. Its policy transparency is higher, although it does not provide an explicit policy inclination. The SNB currently scores very low on operational transparency. Since December 1999 it has had an operational target range for the LIBOR of 100 basis points, but it does not provide an explanation for significant fluctuations within that range. Although it provides an elaborate analysis of macroeconomic developments, only a brief abstract is available in English. ${ }^{24}$ Finally, the SNB gives merely a review of the year, and it does not account for discrepancies between policy outcome and target.

The Swiss National Bank is not very transparent when compared to the other central banks in our sample. There is a lot of scope for greater transparency, especially on the economic and operational aspects.

\subsection{Bank of England}

The Bank of England started off as the most transparent central bank in our sample (with 11 points) and its subsequent rises (to 13) have kept it in the top of the transparency league. The $\mathrm{BoE}$ is an inflation targeter that has attained the maximum score for political, economic and procedural transparency. Its policy transparency is much lower because it does not provide an explicit policy inclination or a prompt explanation after every policy decision. On operational

\footnotetext{
${ }^{23}$ In May 2002, the Riksbank clarified that the attributed reservations against the decision included in the minutes correspond to the only dissents, so that effectively individual voting records are available.

${ }^{24}$ If information were not restricted to be in English, the SNB would gain 0.5 point on item 5.b.
} 
transparency the BoE only misses full marks because there is no evaluation of its policy outcomes that accounts for the contribution of monetary policy.

The Bank of England is very transparent and has been used as an example by many other central banks. Nevertheless, there is still scope for greater policy transparency.

\subsection{Federal Reserve System}

The total score for the Federal Reserve is 10, securing a place in the subtop. The Fed's political transparency is low because it has multiple objectives without an explicit prioritization or quantification, and no explicit, formal instrument independence. Economic transparency is quite high, but it only publishes short-term economic projections for inflation and output at a semiannual frequency. Concerning procedural transparency, the Fed does not publish an explicit policy strategy that describes its monetary policy framework. It has earned full marks on policy transparency since May 1999 when it started to provide an explanation and policy inclination with every policy decision. Its lower score for operational transparency reflects the fact that it only publishes macroeconomic analysis at semiannual frequency and only an informal evaluation of policy outcomes.

The Federal Reserve has high policy transparency, but its political transparency is noticeably less.

These results show that the degree of transparency differs significantly across central banks, even for inflation targeters. In addition, they document significant increases in transparency for several central banks, especially the Swedish Riksbank and the Reserve Bank of New Zealand.

\section{Discussion}

Central banks have many communication tools at their disposal, ranging from monetary policy reports to press conferences. Since these could greatly vary in their informativeness, it is important to focus on the contents rather than the medium of information disclosure. Our index assesses the disclosure of explicit information based on a theory-consistent framework that emphasizes the role of information in the monetary policymaking process. Each question in the index pertains to a distinct item and thereby avoids direct overlap, although it cannot possibly capture all the different ways in which central bank announcements affect people's beliefs. For instance, forecasts and voting records could provide clues about future policy actions. And minutes and policy decisions may reveal information about central bank forecasts. However, such inference is indirect and hard to verify, whereas our index directly addresses each item based on specific criteria.

Nevertheless, information could be conveyed in several ways and there is clearly some substitutability between different communication tools. For instance, a qualitative description of the economic outlook is likely to enrich economic transparency, although it cannot replace the numerical detail provided by quantitative forecasts. A press conference after the policy meeting could contribute to procedural transparency, but in practice it is a poor substitute for the comprehensive account of deliberations that minutes provide. ${ }^{25}$ And more complex ways of conveying monetary policy inclinations could be used instead of a formal policy bias, but in practice they often leave so much leeway for interpretation that they could actually obscure the

\footnotetext{
${ }^{25}$ The introductory statements at ECB press conferences were sometimes jokingly called 'Duisenberg minutes' (named after the first ECB president), but such labels are immaterial for our transparency criteria spelled out in the Appendix.
} 
policy stance. To avoid an exercise in 'reading tea leaves', our index requires explicit information to ensure a certain degree of clarity about each item.

While central banks have become increasingly transparent during the last decade, it is important to realize that there may be trade-offs. For instance, although decision-making by a single central banker may make procedural transparency easier to achieve, a committee of central bankers is likely to make better decisions. The publication of voting records enhances transparency but could affect the independence of monetary policymakers (especially in a monetary union like the EMU), although it could also expose political pressures and facilitate accountability. Commitment to a simple monetary policy rule may be highly transparent but it reduces flexibility to respond to unforeseen circumstances. These examples illustrate that some measures that enhance transparency could have significant drawbacks. They also indicate that a proper assessment of the merits of transparency should be conditional on the monetary policymaking process. Clearly, the way transparency is achieved is not irrelevant.

In addition, it is questionable to simply add the scores of individual items to obtain the transparency index. This should not be interpreted as perfect substitutability across items. Ideally, the weight of each item is established empirically, but lacking comprehensive empirical evidence and facing equivocal theoretical results, we chose to adopt a uniform prior across transparency items. The most fruitful applications of our index are likely to be those that not just rely on the total scores but exploit the rich data we provide on individual items.

Another issue that deserves to be mentioned is the fact that our index is by no means exhaustive. A central bank that obtains full marks need not be perfectly transparent. For instance, the publication of risks to forecasts contributes to economic transparency in the absence of certainty equivalence. And the release of the anticipated forward interest rate path yields more policy transparency than merely providing a policy inclination for the next decision. The score of our index merely indicates that a certain degree of transparency and clarity has been achieved.

Nevertheless, our results establish that there has been a remarkable enhancement of the public communication of monetary policy during our sample period, 1998-2002. At the same time, there have hardly been any modifications to formal disclosure requirements in central bank legislation. Instead, central banks appear to have increased transparency in an attempt to improve credibility of their new low-inflation policies. Outside (political) pressure could also have induced greater transparency. For instance, the publication of macroeconomic projections by the ECB was triggered by the Committee on Economic and Monetary Affairs of the European Parliament in its quarterly Monetary Dialogue with the ECB based on Article 113(3) of the Treaty on European Union and following the advice of its Panel of Experts in their quarterly Briefing Papers. In fact, the European Parliament has repeatedly urged in its Resolutions on the ECB Annual Report that the ECB become more transparent by publishing its macroeconomic forecasts, econometric model, minutes and non-attributed voting records. ${ }^{26}$

Our transparency index focuses on the role that the disclosed information plays in the monetary policymaking process following the framework in Section 2, which makes the index more suitable for an empirical evaluation of theoretical arguments. The empirical literature has started to investigate the macroeconomic effects of central bank transparency. For instance, using cross-section data for 87 countries, Chortareas, Stasavage, and Sterne (2002) find that greater transparency about forward looking analysis is associated with lower average inflation, even

\footnotetext{
${ }^{26}$ See European Parliament Resolutions A5-0035/1999, A5-0169/2000, A5-0225/200, A5-0220/2002 and A5-0237/ 2003.
} 
after controlling for macroeconomic and institutional characteristics such as central bank independence. However, cross-section empirical studies may be problematic because there has been a considerable increase in transparency that is not uniform across countries, as is shown in Table 2. ${ }^{27}$ Geraats and Eijffinger (2004) actually exploit the dynamics in transparency in a timeseries analysis and find that increases in the scores of our index tend to be associated with lower short term interest rates, controlling for macroeconomic circumstances.

Another strand of the empirical literature focuses on financial market responses related to monetary policy. Examples include Clare and Courtenay (2001), Perez-Quiros and Sicilia (2002), Kohn and Sack (2003), Poole and Rasche (2003), Swanson (2004) and Ehrmann and Fratzscher $(2004,2005)$. This literature typically equates greater central bank transparency with better predictability of monetary policy. However, it is important to realize that predictability is determined by both transparency and (the absence of) disturbances. So, predictability and transparency need not correspond. For instance, better predictability of monetary policy found in empirical studies could simply be caused by milder shocks to the economy rather than improved public communication. In addition, frequent changes, such as the modifications to the Policy Targets Agreement in New Zealand, could be promptly disclosed, but they are likely to reduce the long-run predictability of monetary policy.

In practice, monetary policy is never completely predictable. This raises the question to what extent central banks could become more transparent, which is an issue that our index helps to address.

\section{Conclusion}

This paper presents a transparency index for monetary policy that is based on the disclosure of information relevant for the monetary policymaking process. Our index gives rise to some interesting conclusions. The most transparent central banks are the Reserve Bank of New Zealand, the Swedish Riksbank and the Bank of England. The subtop is formed by the Bank of Canada, the European Central Bank and the Federal Reserve. The least transparent central banks in our sample are the Reserve Bank of Australia, the Bank of Japan and the Swiss National Bank.

Although the most transparent central banks in our sample are all inflation targeters, there is remarkable variation in overall transparency among central banks that have adopted inflation targeting. For instance, the Reserve Bank of Australia gets one of the lowest scores. It is striking that the inflation targeters all achieve the maximum score on political transparency, which describes openness about objectives, quantitative targets and institutional arrangements. However, inflation targeting is not a necessary condition for political transparency, as is exemplified by the European Central Bank.

It should be noted that our analysis of the various aspects of central bank transparency is designed to be independent of the monetary policy framework and does not seem to be biased towards inflation targeters, given the large variation within this category. In principle, other monetary policy strategies, like monetary targeting or the ECB's two-pillar strategy, could all obtain the maximum score for any aspect of transparency.

\footnotetext{
${ }^{27}$ For instance, Demertzis and Hughes Hallett (2002) consider the correlation between our transparency index and the mean and variance of inflation and output, but in the unabridged version of this paper (Eijffinger and Geraats, 2004) we show that their results are not robust.
} 
Our analysis shows that central banks put different emphasis on the various aspects of transparency. For instance, the European Central Bank and the Federal Reserve both achieve the same overall score on transparency in 2001. But the ECB has its strength in political transparency, whereas the Fed excels in transparency about its policy decisions in the form of a prompt announcement, explanation and policy inclination. Perhaps, this explains why financial markets perceive the Fed as more transparent than the ECB.

Furthermore, we find that central bank transparency exhibits important dynamics. The scores for several central banks have increased significantly over time, especially for economic and policy transparency, and most notably for the Riksbank. This suggests a general trend towards greater transparency.

Last but not least, this paper provides an index of transparency of monetary policy that systematically distinguishes between various aspects of transparency based on the role the disclosed information plays in the policymaking process. This makes it well-suited to evaluate the theoretical literature on transparency and to assess to what extent central bank transparency really matters.

\section{Acknowledgements}

We acknowledge the excellent research assistance by Annemieke Coldeweijer, Javier Corominas, Carin van der Cruijsen and Tessa Sprokkel. We would also like to thank seminar/ conference participants at the Board of Governors of the Federal Reserve System, the European Central Bank, the European University Institute, De Nederlandsche Bank, the International Monetary Fund, the Riksbank, the EUI workshop "Governance and Legitimacy in EMU" in Florence, the MMF conference "Monetary Policy Transparency" at the Bank of England, and the Annual Congress of the European Economic Association (EEA) in Venice, and, in particular, Mike Artis, Jakub Borowski, Maria Demertzis and the anonymous referees for their detailed comments.

\section{Appendix A}

This appendix contains the exact formulation of the central bank transparency index. The index is the sum of the scores for the answers to the fifteen questions below ( $\min =0, \max =15)$. Note that all questions pertain to published information that is freely available in English.

(1) Political transparency

Political transparency refers to openness about policy objectives. This comprises a formal statement of objectives, including an explicit prioritization in case of multiple goals, a quantification of the primary objective(s), and explicit institutional arrangements.

(a) Is there a formal statement of the objective(s) of monetary policy, with an explicit prioritization in case of multiple objectives?

No formal objective $(\mathrm{s})=0$.

Multiple objectives without prioritization $=1 / 2$.

One primary objective, or multiple objectives with explicit priority $=1$.

(b) Is there a quantification of the primary objective(s)?

$\mathrm{No}=0$.

Yes $=1$.

(c) Are there explicit institutional arrangements or contracts between the monetary authorities and the government?

No central bank, contracts or other institutional arrangements $=0$. 
Central bank without explicit instrument independence or $\operatorname{contract}=1 / 2$.

Central bank with explicit instrument independence or central bank contract (although possibly subject to an explicit override procedure $)=1$.

(2) Economic transparency

Economic transparency focuses on the economic information that is used for monetary policy. This includes economic data, the model of the economy that the central bank employs to construct forecasts or evaluate the impact of its decisions, and the internal forecasts (model based or judgmental) that the central bank relies on.

(a) Is the basic economic data relevant for the conduct of monetary policy publicly available?

The focus is on the release of data for the following five variables: money supply, inflation, GDP, unemployment rate and capacity utilization.

Quarterly time series for at most two out of the five variables $=0$.

Quarterly time series for three or four out of the five variables $=1 / 2$.

Quarterly time series for all five variables $=1$.

(b) Does the central bank disclose the formal macroeconomic model(s) it uses for policy analysis?

$\mathrm{No}=0$.

Yes $=1$.

(c) Does the central bank regularly publish its own macroeconomic forecasts?

No numerical central bank forecasts for inflation and output $=0$.

Numerical central bank forecasts for inflation and/or output published at less than quarterly frequency $=1 / 2$.

Quarterly numerical central bank forecasts for inflation and output for the medium term (one to two years ahead), specifying the assumptions about the policy instrument (conditional or unconditional forecasts) $=1$.

(3) Procedural transparency

Procedural transparency is about the way monetary policy decisions are taken. It involves an explicit monetary policy rule or strategy that describes the monetary policy framework, an account of policy deliberations and how the policy decision was reached.

(a) Does the central bank provide an explicit policy rule or strategy that describes its monetary policy framework?

$\mathrm{No}=0$.

Yes $=1$.

(b) Does the central bank give a comprehensive account of policy deliberations (or explanations in case of a single central banker) within a reasonable amount of time?

No, or only after a substantial lag (more than 8 weeks) $=0$.

Yes, comprehensive minutes (although not necessarily verbatim or attributed) or explanations (in case of a single central banker), including a discussion of backwardand forward-looking arguments $=1$.

(c) Does the central bank disclose how each decision on the level of its main operating instrument or target was reached?

No voting records, or only after substantial lag (more than eight weeks) $=0$.

Non-attributed voting records $=1 / 2$.

Individual voting records, or decision by single central banker $=1$. 
(4) Policy transparency

Policy transparency means prompt disclosure of policy decisions. In addition, it includes an explanation of the decision, and an explicit policy inclination or indication of likely future policy actions.

(a) Are decisions about adjustments to the main operating instrument or target promptly announced?

No, or after a significant lag $=0$.

Yes, at the latest on the day of implementation $=1$.

(b) Does the central bank provide an explanation when it announces policy decisions?

$\mathrm{No}=0$.

Yes, when policy decisions change, or only superficially $=1 / 2$.

Yes, always and including forwarding-looking assessments $=1$.

(c) Does the central bank disclose an explicit policy inclination after every policy meeting or an explicit indication of likely future policy actions (at least quarterly)?

$\mathrm{No}=0$.

Yes $=1$.

(5) Operational transparency

Operational transparency concerns the implementation of the central bank's policy actions. It involves a discussion of control errors in achieving operating targets and (unanticipated) macroeconomic disturbances that affect the transmission of monetary policy. Furthermore, the evaluation of the macroeconomic outcomes of monetary policy in light of its objectives is included here as well.

(a) Does the central bank regularly evaluate to what extent its main policy operating targets (if any) have been achieved?

No, or not very often (at less than annual frequency) $=0$.

Yes, but without providing explanations for significant deviations $=1 / 2$.

Yes, accounting for significant deviations from target (if any); or, (nearly) perfect control over main operating instrument/target $=1$.

(b) Does the central bank regularly provide information on (unanticipated) macroeconomic disturbances that affect the policy transmission process?

No, or not very often $=0$.

Yes, but only through short-term forecasts or analysis of current macroeconomic developments (at least quarterly) $=1 / 2$.

Yes, including a discussion of past forecast errors (at least annually) $=1$.

(c) Does the central bank regularly provide an evaluation of the policy outcome in light of its macroeconomic objectives?

No, or not very often (at less than annual frequency) $=0$.

Yes, but superficially $=1 / 2$.

Yes, with an explicit account of the contribution of monetary policy in meeting the objectives $=1$.

\section{References}

Bernanke, B.S., Laubach, T., Mishkin, F.S., Posen, A.S., 1999. Inflation Targeting: Lessons from the International Experience. Princeton University Press, Princeton, New Jersey.

Bini-Smaghi, L., Gros, D., 2001. Is the ECB sufficiently accountable and transparent? CEPS Working Document No. 169. July. 
Blinder, A., Goodhart, C., Hildebrand, P., Lipton, D., Wyplosz, C., 2001. How Do Central Banks Talk? Geneva Report on the World Economy, vol. 3. ICMB. May.

Buiter, W.H., 1999. Alice in Euroland. Journal of Common Market Studies 37 (2), 181-209 (June).

Chortareas, G., Stasavage, D., Sterne, G., 2002. Does it pay to be transparent? International evidence from central bank forecasts. Federal Reserve Bank of St. Louis Review 84 (4), 99-117 (July/August).

Clare, A., Courtenay, R., 2001. Assessing the impact of macroeconomic news announcements on securities prices under different monetary policy regimes. Bank of England Working Paper no. 125. February.

Cukierman, A., 2002. Are contemporary central banks transparent about economic models and objectives and what difference does it make? Federal Reserve Bank of St. Louis Review 84 (4), 15-35 (July/August).

de Haan, J., Amtenbrink, F., March 2002. A non-transparent European Central Bank? Who is to blame? mimeo, University of Groningen.

de Haan, J., Eijffinger, S.C., 2000. The democratic accountability of the European Central Bank: a comment on two fairytales. Journal of Common Market Studies 38 (3), 393-407 (September).

de Haan, J., Amtenbrink, F., Eijffinger, S.C., 1999. Accountability of central banks: aspects and quantification. Banca Nazionale del Lavoro Quarterly Review 209, 169-193 (June).

Demertzis, M., Hughes Hallett, A., 2002. Central Bank Transparency in Theory and Practice. CEPR Discussion Paper no. 3639. November.

Ehrmann, M., Fratzscher, M. October 2004. Transparency, disclosure and the federal reserve. mimeo, European Central Bank.

Ehrmann, M., Fratzscher, M., 2005. Central bank communication: different strategies, same effectiveness? ECB Working Paper no. 488. May.

Eijffinger, S.C., Geraats, P.M., 2004. How transparent are central banks? Cambridge Working Papers in Economics no. 0411. January.

Fracasso, A., Genberg, H., Wyplosz, C., 2003. How Do Central Banks write? An Evaluation of Inflation Targeting Central Banks. Vol. Special Report 2 of Geneva Reports on the World Economy. Centre for Economic Policy Research.

Fry, M., Julius, D., Mahadeva, L., Roger, S., Sterne, G., 2000. Key issues in the choice of monetary policy framework. In: Mahadeva, L., Sterne, G. (Eds.), Monetary Policy Frameworks in a Global Context. Routledge, London, pp. 1-216.

Geraats, P.M., 2002. Central bank transparency. Economic Journal 112 (483), F532-F565 (November).

Geraats, P.M., 2005. Transparency and reputation: the publication of central bank forecasts. Topics in Macroeconomics 5 (1.1), 1-26.

Geraats, P.M., Eijffinger, S.C., 2004. Does central bank transparency reduce interest rates? Paper Presented at the European Summer Symposium on International Macroeconomics (ESSIM), Tarragona, May 26-29, 2004. (May).

Goodfriend, M., 1986. Monetary mystique: secrecy and central banking. Journal of Monetary Economics 17 (1), $63-92$ (January).

Issing, O., 1999. The eurosystem: transparent and accountable, or "Willem in Euroland". Journal of Common Market Studies 37 (3), $503-519$ (September).

Kohn, D.L., Sack, B.P., 2003. Central bank talk: does it matter and why? Federal Reserve Board Finance and Economics Discussion Series 2003-55 (November).

Morris, S., Shin, H.S., 2002. Social value of public information. American Economic Review 92 (5), $1521-1534$ (December).

Perez-Quiros, G., Sicilia, J., 2002. Is the European Central Bank (and the United States Federal Reserve) predictable? ECB Working Paper no. 192. November.

Poole, W., Rasche, R.H., 2003. The impact of changes in FOMC disclosure practices on the transparency of monetary policy: are markets and the FOMC better "synched"? Federal Reserve Bank of St. Louis Review 85 (2), $1-9$ (January/February).

Svensson, L.E., 2002. Inflation targeting: should it be modeled as an instrument rule or a targeting rule? European Economic Review 46 (4-5), 771-780 (May).

Swanson, E.T., 2004. Federal reserve transparency and financial market forecasts of short-term interest rates. Federal Reserve Board Finance and Economics Discussion Series 2004-6 (February).

Winkler, B., 2002. Which kind of transparency? On the need for effective communication in monetary policy-making. Ifo-Studien 48 (3), 401-427. 